\title{
Determining the geochemical hazard of drinking water: Case studies from the Novogorsk and the Aprelevka districts, Moscow Region, Russia
}

\author{
K.Y. Mikhaylichenko ${ }^{1}$, A.Y. Dorontsova ${ }^{1}$, O.A. Maksimova $^{1}$, I.A. Adarchenko ${ }^{1,}$, and A.I. Kurbatova ${ }^{1}$ \\ ${ }^{1}$ Peoples' Friendship University of Russia (RUDN. Ecological Faculty. Russia, Moscow, Podolskoye shosse 8s5, 115093
}

\begin{abstract}
This study analyzed the composition of tap water quality in the centralized water supply systems of Novogorsk and Aprelevka districts of the Moscow region, Russia for compliance with hygienic standards as an assessment of health risk. The formulation of this topic results from the urgency of environmental safety within urban areas, which requires the development of theoretical and methodological capabilities for the forecast and management of technological risks associated with anthropogenic pollution.
\end{abstract}

\section{Introduction}

Currently, the water supply of the Moscow region is almost entirely based on the use of groundwater from three aquifers within coal-bearing geological formations, each of which has some deviation from the sanitary and hygienic standards caused by natural causes [1-3]. This groundwater supplies an average $90 \%$ of the total water consumption [2, 4]. This water supply is derived from five aquifers, three of which are used for water supply in the southwest sector of the Moscow Region: Podolsko-Myachkovsky, Kashirsky, and Aleksinsko-Protvinsky [4]. Important characteristics of the aquifers are shown in Table 1.

Table 1. Characteristics of the groundwater aquifers in the Podolsko-Myachkovsky, Kashirsky, and Aleksinsko-Protvinsky districts of Moscow.

\begin{tabular}{|c|c|c|c|c|c|}
\hline Aquifer & $\begin{array}{c}\text { Aquifer } \\
\text { Depth (m) }\end{array}$ & $\begin{array}{l}\text { Geological } \\
\text { Formation }\end{array}$ & $\begin{array}{c}\text { Depth to } \\
\text { Groundwater Table } \\
(\mathrm{m})\end{array}$ & $\begin{array}{c}\text { Annual Withdrawal } \\
\text { (million } \mathrm{m}^{3} / \text { year) }\end{array}$ & Primary Use \\
\hline $\begin{array}{c}\text { Podolsko- } \\
\text { Myachkovsky }\end{array}$ & $10-300$ & \multirow{3}{*}{ Carboniferous } & $25-180$ & 1.58 & \multirow{3}{*}{ potable water } \\
\hline Kashirsky & $50-180$ & & $80-160$ & \multirow[b]{2}{*}{1.62} & \\
\hline $\begin{array}{l}\text { Aleksinsko- } \\
\text { Protvinsky }\end{array}$ & $115-130$ & & $20-80$ & & \\
\hline
\end{tabular}

In addition to the quantitative characteristics of resources and groundwater reserves, an important role is played by their quality. The groundwater of the coal-bearing aquifers in the Moscow region have a inconstant composition that varies from hydrocarbonate to hydrocarbonate-sulphate, hydrocarbonate-chloride and various intermediate compositions [4]. Total dissolved contents of groundwater in the zones of exploitation varies from 0.3 to $0.7 \mathrm{~g} / \mathrm{L}$, increasing in some urban areas and regularly increasing with increasing depth of the horizons to the northeast. The components that significantly impair the quality of groundwater in the region are primarily hardness, $\alpha$-radioactivity, $\mathrm{Fe}, \mathrm{Li}, \mathrm{F}$, and $\mathrm{Sr}[6]$.

The carbonic aquifer system has widespread distribution in the territory of the Novogorsk District. In general, the aquifer system is considered as a complex combination of aquifers and relatively impermeable layers with a hydraulic interconnection of the water-bearing stratigraphic units. The water-bearing rocks are unevenly fractured limestones and dolomites that contain interlayers of clay and marl. The complex is represented by the Upper Carboniferous Kasimovsky aquifer (C3k), the Middle Carboniferous Podolsko-Myachkovsky aquifer (C2pd-mc), and the Lower Carboniferous Oksko-Protvinsky aquifer (C1oc-pr) [2, 3]. These water-bearing rocks are intensively exploited, as the primary source for water supply in the greater Moscow region and the city itself. The waters of the carbonic aquifer are reliably protected from surface pollution by a thick $(12-20 \mathrm{~m})$ stratum of overlying Jurassic clay [4]. Anthropogenic pollution is associated only with the state of the water supply [7].

\footnotetext{
${ }^{*}$ Corresponding author: adarchenok@ yandex.ru
} 
The territory of Khimki City suffers from a deficit of groundwater supply, which has been addressed by using substandard water for drinking water supply. This has been accomplished by diluting water from water supply systems and by building water treatment plants. For example, the installation of technology for the removal of Fe from underground water allows the use for drinking water supply that previously did not meet the specifications for human consumption [2].

Two artesian aquifers are present under the territory of the Aprelevka District: Kashirsky and PodolskoMyachkovsky. The Kashirsky aquifer lies at a depth of 35 to $90 \mathrm{~m}$, while the Podolsko-Myachkovsky is below $130 \mathrm{~m}$. The productivity of the Podolsko-Myachkovsky aquifer is several times greater than that the Kashirsky aquifer. Therefore, wells are drilled to a depth of about 150 to $200 \mathrm{~m}$ for industrial purposes in the area of Aprelevka District [3]. The groundwater from each aquifer has its own characteristics, which differ by region. Sulfates predominate in the Kashirsky aquifer, while the Podolsko-Myachkovsky aquifer has an elevated content of fluorine and iron. Increased water hardness is characteristic of almost all sources in the Moscow region [4]. Water from these sources is not distilled or treated.

\section{Methodology}

Sampling was undertaken according to Russian standards following GOST 31861-2012. "Water. General Requirements for Sampling”, GOST R 56237-2014 (ISO 5667-5:2006) "Drinking Water. Sampling on Water Treatment Stations and in Piped Distribution Systems". Assessment of drinking water quality was carried out in accordance with SanPiN 2.1.4.1074-01. Determination of both qualitative and quantitative compositions were determined by the analytical methods of photometry, ion chromatography, atomic absorption, potentiometry, mass spectrometry and fluorescence. The risk assessment methodology was chosen as an effective tool for preliminary analysis of the situation, which does not require significant financial or organizational costs and, at the same time, provides information for further control actions [7, 10]. Risk assessment was performed in accordance with the "Guidelines for the Assessment of Risk to Public Health Under Exposure to Environmental Pollution Chemicals" [12].

\section{Results and Discussion}

There have been previous studies of the water quality of subsurface waters of Moscow and the region surrounding the city, but novelty of this is its focus on the rapidly-growing districts and the sudden ageing of the water supply and water purifying systems. For these reasons it was very important to analyze concentrations of more common elements of water of these regions. This kind of research is the first of recent years. Average reading of studies of potable water samples from centralized water supplies from four months of control according to Russian standards at accredited laboratory shows that the water supply of the Aprelevka District does not meet the requirements of SanPiN 2.1.4.107401 in terms of total water hardness $(7 \circ \mathrm{g}$ compared to a standard of $<7 \circ \mathrm{g})$. At the same time, the excess of $\mathrm{F}$ observed in the Novogorsk District is three times above the standard ( $4.2 \mathrm{mg} / \mathrm{cu} . \mathrm{dm}$ compared to a requirement of $1.5 \mathrm{mg} / \mathrm{cu} . \mathrm{dm})$.

Results of the analysis of potable water samples of the centralized water supply systems of the Aprelevka and Novogorsk Districts are presented in the Table 1. Hygienic standards adopted by SanPiN 2.1.4.1074-01 "Potable Water. Hygienic Requirements for Water Quality of Centralized Drinking Water Supply Systems - Quality Control” [13]. Data analysis indicates that the quality of the water from Novogorsk does not meet the regulatory requirements due to its high fluoride content of $4.2 \mathrm{mg} / \mathrm{l}$ compared to a standard of not more than $1.5 \mathrm{mg} / \mathrm{l}$ (Table 2). Elevated concentrations of $\mathrm{F}, \mathrm{Li}$, and $\mathrm{Sr}$ affect a significant part of the Moscow region groundwater supply. The increased content of these trace constituents in the water of all aquifers in the region has a natural origin, with the source of their elevated concentrations in groundwater are minerals in the water-bearing rocks.

In some areas that are rich in F-containing minerals, the concentration of fluoride in groundwater can reach and even exceed $10 \mathrm{mg} / \mathrm{L}$ [1]. Another source of substandard groundwater can be withdrawal from the underlying lower Carboniferous aquifers. This occurs in areas with intensive water intake and leads mainly to an increase in the concentration of fluorides and sulfates. The source of $\mathrm{F}$ in water are soils and the underlying rocks, in which there are soluble F-containing minerals like apatite and tourmaline. The groundwater from most sources contains lower concentrations of $\mathrm{F}$, but high concentrations of $\mathrm{F}$ are more common in artesian well waters.

Table 2. Composition of public water supply in the Aprelevka and Novogorsk districts.

\begin{tabular}{|c|c|c|c|c|}
\hline \multirow{2}{*}{ : } & \multirow{2}{*}{ 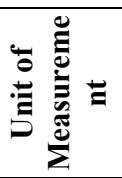 } & \multirow{2}{*}{ 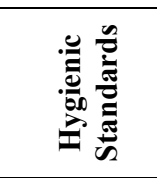 } & \multicolumn{2}{|c|}{ Indicator Values } \\
\hline & & & Aprelevka & Novogorsk \\
\hline Smell at $20^{\circ} \mathrm{C}$ & grade & not above 2 & absent, 0 & absent, 0 \\
\hline Chromacity & degree & $<20$ & 1.1 & $<1$ \\
\hline Turbidity & FTU & $<2.6$ & $<1$ & $<1$ \\
\hline
\end{tabular}




\begin{tabular}{|c|c|c|c|c|}
\hline Total Hardness & $\begin{array}{l}\text { degree of } \\
\text { hardness }\end{array}$ & 1.5 to 7.0 & 7.0 & 1.1 \\
\hline $\begin{array}{c}\text { Permanganate } \\
\text { Oxidizability }\end{array}$ & $\mathrm{mgO} / \mathrm{L}$ & $<5.0$ & 1.2 & 0.5 \\
\hline $\mathrm{pH}$ & degree & 6 to 9 & 7.2 & 7.6 \\
\hline Total Fe & $\mathrm{mg} / \mathrm{L}$ & 0.3 & $<0.05$ & 0.14 \\
\hline $\mathrm{Mn}$ & $\mathrm{mg} / \mathrm{L}$ & 0.1 & 0.06 & $<0.001$ \\
\hline $\mathrm{Cu}$ & $\mathrm{mg} / \mathrm{L}$ & 1.0 & 0.009 & $<0.001$ \\
\hline $\mathrm{Zn}$ & $\mathrm{mg} / \mathrm{L}$ & 5.0 & 2.8 & 0.008 \\
\hline $\mathrm{Cd}$ & $\mathrm{mg} / \mathrm{L}$ & 0.001 & $<0.0001$ & $<0.0005$ \\
\hline $\mathrm{Pb}$ & $\mathrm{mg} / \mathrm{L}$ & 0.3 & 0.06 & 0.06 \\
\hline As & $\mathrm{mg} / \mathrm{L}$ & 0.05 & $<0.005$ & 0.05 \\
\hline $\mathrm{Na}$ & $\mathrm{mg} / \mathrm{L}$ & 200 & 14 & 99 \\
\hline K & $\mathrm{mg} / \mathrm{L}$ & 20 & 2.7 & 6.5 \\
\hline $\mathrm{Ca}$ & $\mathrm{mg} / \mathrm{L}$ & 130 & 97.3 & 9.8 \\
\hline $\mathrm{Mg}$ & $\mathrm{mg} / \mathrm{L}$ & 50 & 26 & 7.2 \\
\hline $\mathrm{Sr}$ & $\mathrm{mg} / \mathrm{l}$ & 7 & 0.29 & 1 \\
\hline $\begin{array}{l}\text { Total Base } \\
\text { Number }\end{array}$ & $\mathrm{mmol} / \mathrm{L}$ & 6.5 & 6,0 & 4.8 \\
\hline Free Alkalinity & $\mathrm{mmol} / \mathrm{L}$ & 6.5 & $<0.1$ & $<0.1$ \\
\hline $\mathrm{HCO}_{3}$ & $\mathrm{mg} / \mathrm{L}$ & 400 & 365 & 292 \\
\hline $\mathrm{NH}_{3}$ & $\mathrm{mg} / \mathrm{L}$ & 1.5 & 0.08 & $<0.03$ \\
\hline $\mathrm{F}$ & $\mathrm{mg} / \mathrm{L}$ & 1.5 & 0.8 & 4.2 \\
\hline $\mathrm{Cl}$ & $\mathrm{mg} / \mathrm{L}$ & 350 & 50 & 5.1 \\
\hline $\mathrm{SO}_{4}$ & $\mathrm{mg} / \mathrm{L}$ & 500 & 29 & 23 \\
\hline $\mathrm{NO}_{3}$ & $\mathrm{mg} / \mathrm{l}$ & 45 & $<0.5$ & 2.3 \\
\hline $\begin{array}{c}\text { Electric } \\
\text { Conductance }\end{array}$ & $\mu \mathrm{S} / \mathrm{cm}$ & - & 674 & 486 \\
\hline $\begin{array}{l}\text { Total Dissolved } \\
\text { Solids }\end{array}$ & $\mathrm{mg} / \mathrm{L}$ & 1000 & 472 & 340 \\
\hline
\end{tabular}

The presence of $\mathrm{Cd}$ in drinking water of Novogorsk and Aprelevka is explained by its possible entry during leaching of soils containing polymetallic and copper ores as a result of decomposition of aquatic organisms capable of accumulating it. $\mathrm{Cd}$ is present in water in a dissolved forms (sulfate, chloride, cadmium nitrate) and contained in the composition of organo-mineral complexes. The content of $\mathrm{Cd}$ in water is significantly influenced by the $\mathrm{pH}$ of the medium (in an alkaline medium, Cd precipitates as hydroxide), as well as sorption processes [14]. According to the World Health Organization (WHO), the content of Cd in unpolluted natural waters is significantly less than $1 \mathrm{mg} / \mathrm{L}$ (about 0.02 to $0.3 \mu \mathrm{g} / \mathrm{L}$ ). However, in polluted areas, its concentration in water can reach tens of $\mu \mathrm{g} / \mathrm{L}$ [11]. There is a definite, though not great danger of contamination of drinking water due to the processes of Zn corrosion of galvanized pipes and other plumbing fittings, since $\mathrm{Zn}$ often contains $\mathrm{Cd}$ impurities [15]. The WHO standards are stricter than Russian standards, and in further studies it is advisable to compare measurements with the WHO standards.

Calculations of the integral indicator of the potable water quality on the basis of risk assessment were carried out for water in the Aprelevka and Novogorsk Districts. For this purpose, it was necessary to assess the risk of human intake of drinking water containing chemicals that are characterized by an olfactory-reflex effect to exposure, the total noncarcinogenic risk of the chemical with toxicological effect of exposure, as well as the total carcinogenic risk to public health. Based on the guidelines, the value of the integral indicator of the potable water quality should not exceed one [16]. The results of calculation of integrated indicators of drinking water quality are presented in the Table 3. 
Table 3. Integral indicator of the potable water quality in the Aprelevka and Novogorsk Districts.

\begin{tabular}{|c|c|c|c|c|}
\hline District & $\begin{array}{c}\text { Type of } \\
\text { Risk }\end{array}$ & $\begin{array}{l}\text { Estimated } \\
\text { Value }\end{array}$ & $\begin{array}{l}\text { Risk in Relation to } \\
\text { Acceptable Value }\end{array}$ & $\begin{array}{l}\text { Integral } \\
\text { Indicator }\end{array}$ \\
\hline \multirow{3}{*}{ Aprelevka } & RORE $^{*}$ & 0.007 & 0.07 & \multirow{3}{*}{1.73} \\
\hline & $\mathrm{NR}^{*}$ & 0.058 & 1.16 & \\
\hline & $\mathrm{CR}^{*}$ & 0.000005 & 0.5 & \\
\hline \multirow{3}{*}{ Novogorsk } & RORE & 0.002 & 0.002 & \multirow{3}{*}{3.15} \\
\hline & NR & 0.132 & 2.648 & \\
\hline & $\mathrm{CR}$ & 0.000005 & 0.5 & \\
\hline
\end{tabular}

Thus, as a result of risk assessment considering oral intake with drinking water of the chemicals characterized by olfactory-reflex effect in two settlements it was revealed that the level of risk is minimal (i.e. acceptable). Assessment of the total lifetime non-carcinogenic risk to the health of the population of Aprelevka and Novogorsk Districts through the consumption of tap water revealed that the level of carcinogenic risk is satisfactory. This water is characterized by the presence of complaints of the population on the discomfort that arises under the influence of, e.g. unpleasant odors, reflex reactions, etc. The evaluation of the carcinogenic risk after oral exposure to chemical substances with toxicological effects shows that the level of risk in the Aprelevka and Novogorsk Districts is acceptable. However, as a result of the integrated assessment of the potable water quality undertaken here, it was observed that the integrated indicators for the Aprelevka and Novogorsk Districts do not correspond to the permissible value, which is associated in both cases with exceeding the acceptable values for non-carcinogenic risk. Exceeding the value of acceptable risk for at least one of its types requires additional measures to regulate water quality [17].

Because high concentrations of fluorides have been identified, measures should be taken to improve potable water with the introduction of new technologies to improve the water treatment system. It seems necessary to develop systems of measures to minimize risks, to conduct systematic observations of the content of hazardous impurities in drinking water, and to inform the public about health risks. Due to the very low levels of metal concentrations in drinking water at which risks can be considered acceptable, it seems reasonable to improve the methods of quantitative determination of elements in drinking water. Recommendations should be made to supervisory authorities to focus on the specifics of the geochemical territory and include them in monitoring and laboratory research programs in the supervision of impurities that have high levels in the environment

\section{References}

1. L.F. Goldovskaya-Peristaya, et al., Sci News of BelSU, Series: Nat. Sci. 9/80, 124-130 (2010)

2. Schemes of Water Supply and Sanitation of Khimki Urban District for the Period up to 2024 (2015)

3. Schemes of Water Supply and Sanitation of the Urban Settlement Aprelevka Naro-Fominsky Municipal District of the Moscow Region for the Period from 2017 to 2032 (2017)

4. M.S. Orlov, K.E. Pitevoy, Hydrogeoecology of Cities [Text]: Study Guide for Students Enrolled in the Direction of Training 020700 - Geology (2013)

5. G.G. Onishchenko, On the State and Measures to Ensure the Safety of Drinking Water Supply to the Population of the Russian Federation, 3, 4 (2010)

6. A.Y. Korshunova, et al., Urban Land Env, 1, 80-82 (2014)

7. N.V. Zaytseva, I.V. May, Ars Administrandi, 2, 30-39 (2011)

8. A.Z. Isakov, et al., Hygiene Sanitation, 1, 4-5 (2009)

9. I.V. May, et al., Public Health Envir, 11, 28-30 (2010)

10. Guidelines for Drinking-Water Quality - E 4 (2011)

11. L. Jarup, Br Med Bull, 68, 167-182 (2003)

12. Drinking Water Hygienic Requirements for Water Quality of Centralized Drinking Water Supply Systems. Quality Control. Sanitary-Epidemiological Rules and Regulations. SanPiN 2.1.4.1074-01 URL: http://www.docload.ru/Basesdoc/9/9742/index.htm.

13. D.A. Klyuchnikov, Comprehensive Assessment of the Quality Of Drinking Water and its Impact on Public Health On the Example of the Ussuri Urban District (2014)

14. I.V. Proskurina, A.P Belousova, Water: Chem Ecol, 12, 2-11 (2010)

15. Federal Center for Hygiene and Epidemiology, Rospotrebnadzor, Integral Assessment of Drinking Water of Centralized Water Supply Systems in Terms of Chemical Safety Indicators: Methodical Recommendations (2011)

16. K. Y. Mikhaylichenko, et al., PFUR Bulletin. Series: Ecology Life safety 4, 106-113 (2014) 